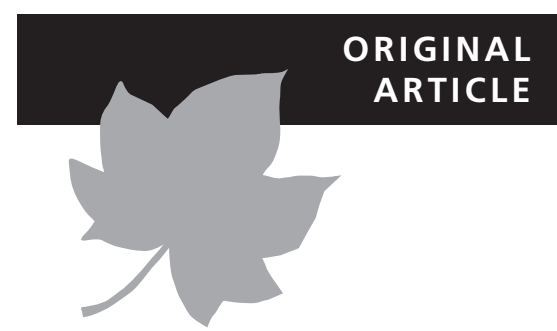

\title{
Influence of past and future climate changes on the distribution of three Southeast Asian murine rodents
}

\author{
Alice Latinne $^{1,2,3 \star}$, Christine N. Meynard ${ }^{4,5}$, Vincent Herbreteau ${ }^{6}$, \\ Surachit Waengsothorn ${ }^{7}$, Serge Morand $d^{2,8,9}$ and Johan R. Michaux ${ }^{1,10}$
}

${ }^{1}$ Conservation Genetics Unit, Institut de Botanique, University of Liege, Liège, Belgium, ${ }^{2}$ Institut des Sciences de l'Evolution, CNRS-IRD-UM2, Université de Montpellier 2, Montpellier, France, ${ }^{3}$ Department of Parasitology, Faculty of Veterinary Medicine, Kasetsart University, Bangkok, Thailand, ${ }^{4}$ INRA, UMR CBGP (INRA/IRD/CIRAD/ Montpellier SupAgro), Campus international de Baillarguet, CS 30016 Montferrier-sur-Lez cedex, France, ${ }^{5}$ Virginia Institute of Marine Science, College of William \& Mary, Gloucester Point, VA, USA, ' IRD, UMR ESPACE-DEV (IRD, UM2, UAG, UR), Station SEAS-OI, Saint-Pierre, France, ${ }^{7}$ Environment and Resources Technology Department, Thailand Institute of Scientific and Technological Research, Pathum Thani, Thailand, ${ }^{8}$ Walai Rukhavej Botanical Research Institute, Mahasarakham University, Maha Sarakham, Thailand, ${ }^{9}$ CNRS-CIRAD, Centre Infectiologie Christophe Mérieux $d u$ Laos, Vientiane, Laos PDR, ${ }^{10}$ CIRAD, UR AGIRs, Campus International de Baillarguet, Montpellier, France

${ }^{*}$ Correspondence: Alice Latinne, Conservation Genetics Unit, Institut de Botanique (B22), University of Liege, Boulevard du Rectorat, 27, 4000 Liège, Belgium.

E-mail: alice.latinne@gmail.com

\section{ABSTRACT}

Aim We tested the influence of Pleistocene climatic fluctuations and the potential effect of future climate change on Southeast Asian small mammal distributions using two forest-dwelling (Leopoldamys herberti and Leopoldamys sabanus) and one karst (Leopoldamys neilli) endemic rodent species as models.

Location Southeast Asia.

Methods We used presence-absence data of genetically identified individuals, bioclimatic variables and species distribution modelling techniques to predict potential distributions of the three studied species under current, past [Last Interglacial (LIG) and Last Glacial Maximum (LGM)] and future conditions. We applied a variety of modelling techniques and then used consensus techniques to draw up robust maps of potential distribution ranges at all stages.

Results According to our models, these three Leopoldamys species did not experience significant range contraction during the LGM. Our models revealed substantial range contraction during the LIG for $L$. herberti in northern Indochina, while its distribution expanded in southern Indochina. Evidence of a southward range expansion during that period was also obtained for L. neilli, whereas L. sabanus remained widely distributed in insular Southeast Asia but experienced a range contraction on the Thai-Malay Peninsula. The two future climate change scenarios used predicted that large climatically suitable areas would still be available in the future for the three species.

Main conclusions Our model predictions contradict the well-established hypothesis that Southeast Asian forest-dwelling species were confined to small refugia during the LGM. Moreover, our results suggest that some Southeast Asian taxa may have been distributed in their refugial state during the LIG rather than the LGM. This could be because of vegetation changes that may have occurred at that time as a result of the increased seasonality observed during the LIG. These Pleistocene refugia may have been localized in northern Indochina but our study also revealed that southern Indochina could provide major potential refugia.

\section{Keywords}

Climate change, Last Glacial Maximum, Last Interglacial, Leopoldamys, Murinae, Pleistocene, rodents, Southeast Asia, species distribution modelling.

\section{INTRODUCTION}

The distributional response of plant and animal species to Pleistocene climate changes has been studied widely in Europe and North America. In these temperate regions, the contraction of the northern range of many species during glacial periods, followed by northward recolonizations from southern refugia during interglacial periods, has been frequently documented (Hewitt, 2004; Michaux et al., 2005; and references therein). However, recent studies have demonstrated that this pattern does not always apply. For example, northern regions of central and eastern Europe have also acted as 
refugia for some temperate plant and animal species (Kotlík et al., 2006; Stewart et al., 2010). In the tropics, the effects of the Pleistocene cyclic glaciations were less intense than in temperate regions but it has been suggested that the cooler arid climate during glacial periods led to the formation of isolated rain forest refugia in mountainous areas (BrandonJones, 1996; Haffer, 1997). However, little is currently known regarding the distributional consequences of Pleistocene climatic fluctuations for tropical species, especially in Southeast Asia.

Southeast Asia encompasses four biogeographical subregions that host around $18 \%$ of all plant and animal species on Earth (Myers et al., 2000). A complex geological history and repeated climatic fluctuations over the last few million years have influenced the biogeographical patterns of many species in the region and created a unique fauna characterized by high levels of endemism (Woodruff, 2010). In Asia, the glacial advance was less extensive than in Europe or North America. Two main climate-related events may have contributed to diversification and population divergence during the Pleistocene in Southeast Asia. First, drastic changes in the Southeast Asian landscape occurred throughout the Pleistocene as a result of sea-level variations. Parts of the Sunda shelf were repeatedly exposed and submerged during this time period (Voris, 2000). Consequently, temporary land bridges were frequently created between the mainland and insular regions of Sundaland, possibly enabling biotic migrations from the mainland to the archipelago (Heaney, 1986). Second, Pleistocene climatic fluctuations also contributed to vegetation changes in Southeast Asia. However, the Quaternary distribution of forest types in this region is still uncertain and highly debated (Hope et al., 2004; Bird et al., 2005; Cannon et al., 2009; Wurster et al., 2010).

Many Sundaic bird and mammal species did not seem to experience significant population fragmentation during the Last Glacial Maximum (LGM; 19-26.5 ka; Peltier \& Fairbanks, 2006) (Gorog et al., 2004; Lim et al., 2010; Lim \& Sheldon, 2011) but Indochinese forest-dwelling mammals (Brandon-Jones, 1996; Luo et al., 2004; Patou et al., 2010), birds (Fuchs et al., 2008) and insects (Morgan et al., 2011) may have been restricted to allopatric rain forest refugia in some northern Southeast Asian mountain ranges during Pleistocene glacial periods before expanding southwards during interglacial periods. However, recent studies combining phylogeographical analyses and species distribution modelling (SDM) have revealed, surprisingly, a severe range contraction for several bird species in southern China during the Last Interglacial (LIG; 116-130 ka; Shackleton et al., 2003), while similar distributions have been noted for these species when comparing present-day and LGM patterns (Dai et al., 2011; Zhao et al., 2012; Wang et al., 2013). The invasive mosquito, Aedes albopictus, was also distributed widely in Southeast Asia during the LGM according to SDM projections (Porretta et al., 2012). However, SDM approaches have never been applied to past distributions of Southeast Asian forest mammals, and the effects of Quaternary climate changes on mammal distributions in Southeast Asia are not yet clearly understood.

In this study, we selected three long-tailed giant rat species belonging to the genus Leopoldamys (Rodentia, Muridae) to assess the influence of Pleistocene climatic fluctuations and the potential effect of future climate change on small forest mammal distributions in Southeast Asia using SDMs. These are interesting model species because their distinct distributions span a large portion of Southeast Asia and they have contrasting ecological and forest habitat requirements. Leopoldamys sabanus (Thomas, 1887) (lineage L5 in Balakirev et al., 2013) is semi-arboreal and found in lowland Sundaic forest habitats. Leopoldamys herberti (Kloss, 1916) (lineage L1) occurs in primary and secondary evergreen lowland and montane forests of Indochina. Leopoldamys neilli (Marshall, 1977) (lineage L2) is endemic to limestone karsts of Indochina. These giant rats may also play an important role in forest regeneration as they are better seed dispersers than many other rodent species in Southeast Asia and China (Wells et al., 2009; Chang \& Zhang, 2011).

The taxonomy of Leopoldamys species has been reviewed recently and is now better understood. Six species were recognized by Musser \& Carleton (2005). Balakirev et al. (2013) and Latinne et al. (2013a), however, suggested that an additional species existed in the Indochinese region, i.e. L. herberti, a phylogenetic lineage that was previously thought to belong to Leopoldamys edwardsi (Pagès et al., 2010). Evidence of $L$. herberti has been found in northern Thailand, Laos, Vietnam and Cambodia, but its occurrence in neighbouring countries has not been documented. Leopoldamys neilli has been described in Thailand but has also recently been discovered in northern Laos and Vietnam (Balakirev et al., 2013; Latinne et al., 2013a). The distribution of L. sabanus was previously thought to encompass both the Indochinese and Sundaic subregions, but Balakirev et al. (2013) and Latinne et al. (2013b) have shown that it is probably a Sundaic species with southern Thailand the northern limit of its range: it does not occur further north in Indochina. These molecular studies have therefore revealed important misclassification errors in previous studies, showing that current knowledge of these species distributions is uncertain, as is the conservation status of the three species. Leopoldamys neilli was previously classified as Endangered on the IUCN Red List but is now considered Data Deficient because of the lack of knowledge regarding its distribution and ecological requirements (Lunde \& Aplin, 2008). Leopoldamys sabanus is listed as Least Concern because of its presumed large distribution and populations (Lunde et al., 2008). The conservation status of $L$. herberti has never been assessed separately because this lineage was previously thought to belong to $L$. edwardsi.

Our study, involving SDM techniques, had two main objectives. First, we wanted to assess the influence of Pleistocene climatic fluctuations on L. neilli, L. herberti and L. sabanus distributions. The aim was to determine whether they were confined to small forest refugia during the Pleistocene 
glacial or interglacial periods and, if so, to localize these potential refugia. Maps of projected past and current distributions of these species provide a link between current environmental occupancy and biogeographical hypotheses based on molecular data that have been proposed in previous studies. Our second objective was to assess the potential impact of future climate change on the distribution of the three species.

\section{MATERIALS AND METHODS}

\section{Species occurrence data}

We focused only on occurrence data of genetically identified specimens because of the identification problems described above. We used a combination of locality points that we gathered during several field surveys and additional records from previous studies for which sequences were available. Field surveys in Thailand, Laos and Cambodia were carried out between 2002 and 2012. Most of the surveyed regions were sampled at least twice (during dry and rainy seasons), 1 or 2 years apart. Several habitat types, including human settlements, forests, cultivated areas and limestone karsts, were surveyed using georeferenced lines of live-capture cage traps during three consecutive nights. The cytochrome $b$ gene $(c y t b)$ and/or the cytochrome $c$ oxidase subunit I gene (COI) were amplified for all Leopoldamys samples, as described in Pagès et al. (2010) and Latinne et al. (2013b). Besides our own sampling, we added five Laotian $L$. herberti specimens from the Australian National Wildlife Collection (CSIRO, Canberra, ACT) and two L. sabanus specimens from Borneo collected by Wells et al. (2007), as well as GenBank records for which geographical coordinates or a precise geographical locality were specified (as of 15 June 2013). These GenBank sequences included those published in Gorog et al. (2004) and Balakirev et al. (2013) as well as three unpublished sequences of specimens from the Royal Ontario Museum (Toronto, ONT) (see Appendix S1 in the Supporting Information for GenBank accession numbers of all sequences).

Phylogenetic analyses were then performed on the complete dataset using Bayesian inference and maximum likelihood approaches (see Appendix S1 for more details). These phylogenetic analyses allowed us to assign each individual unambiguously to one of the genetic lineages defined in Balakirev et al. (2013) and Latinne et al. (2013a). All samples belonging to the lineages L1 (L. herberti), L2 (L. neilli) and L5 (L. sabanus) were included.

The data were represented in a geographical information system using ArcGIS 9.3 (ESRI, Redlands, CA, USA). They included 42 positive records for $L$. neilli (31 in Thailand, five in Laos, five in Vietnam and one in China), 42 for L. herberti (25 in Thailand, eight in Laos, seven in Vietnam and two in Cambodia), 25 for L. sabanus (17 in Thailand, one in Malay Peninsula, six in Borneo and one in Sumatra) and a total of 428 surveyed sites (268 in Thailand, 72 in Laos, 11 in Viet- nam, 68 in Cambodia, one in China, one in Malay Peninsula, one in Sumatra and six in Borneo). These localities were overlaid on a $10^{\prime}$-resolution grid corresponding to the environmental data resolution (see below). Any points falling within the same grid cell were coded as a single presence or absence location. Absence records corresponded to the surveyed sites where the Leopoldamys species were not encountered. After the overlay, we were left with 31, 32 and 20 presence records for $L$. neilli, L. herberti and L. sabanus, respectively, with 122 grid cells overall having a presence or absence record (Fig. 1).

\section{Environmental variables and climatic scenarios}

For potential distribution projections, we considered an area including the Indochinese and Sundaic subregions, as well as Bangladesh and north-eastern India (Fig. 1a). This area encompasses two relevant biogeographical regions where the genus Leopoldamys is currently distributed and where fossils of this genus have been discovered (Medway, 1977; Zheng, 1993; Chaimanee, 1998; Storm et al., 2005; Bacon et al., 2006).

Current, past and future climatic scenarios were downloaded from the WorldClim database (Hijmans et al., 2005; http://www.worldclim.org). Past scenarios were those of the LGM (19-26.5 ka) and LIG (116-130 ka). These two time periods correspond to two opposite climatic extremes during the Pleistocene that may represent key events in the evolutionary history of forest-dwelling species in Southeast Asia and may have strongly affected their distribution.

We selected future climate projections for the end of the century (data centred on 2080 and averaged across a decade), when several studies have predicted that the impacts of climate change will be more pronounced than earlier in the century (e.g. Butler et al., 2012; Bertelsmeier et al., 2013), in order to explore potential long-term range shifts of the species. To explore uncertainties related to future climate projections, we compared two scenarios from the Canadian Center for Climate Modeling and Analysis (Gatineau, QC) repository, i.e. $\mathrm{B} 2 \mathrm{~A}$ and $\mathrm{A} 1 \mathrm{~B}$, which cover a moderate to medium range of future greenhouse gas emissions and socioeconomic developments. The A1B scenario is one of very rapid economic growth associated with a projected global average surface warming of $2.8^{\circ} \mathrm{C}\left(1.7-4.4^{\circ} \mathrm{C}\right)$ and an estimated sea level rise of $0.21-0.48 \mathrm{~m}$ for the end of $21 \mathrm{st}$ century. The B2A scenario is more conservative and based on local environmental sustainability: it produces a less dramatic climate change projection, with an estimated warming of $2.4{ }^{\circ} \mathrm{C}\left(1.4-3.8^{\circ} \mathrm{C}\right)$ and an estimated sea level rise of 0.20 $0.43 \mathrm{~m}$ (IPCC, 2007).

Nineteen bioclimatic variables representing annual trends, seasonality and extreme or limiting environmental factors were used (http://worldclim.org/bioclim). Data were downloaded and used at $10^{\prime}$ resolution or resampled at that resolution (in the case of the LGM and LIG) by using block statistics in ArcGIS. 


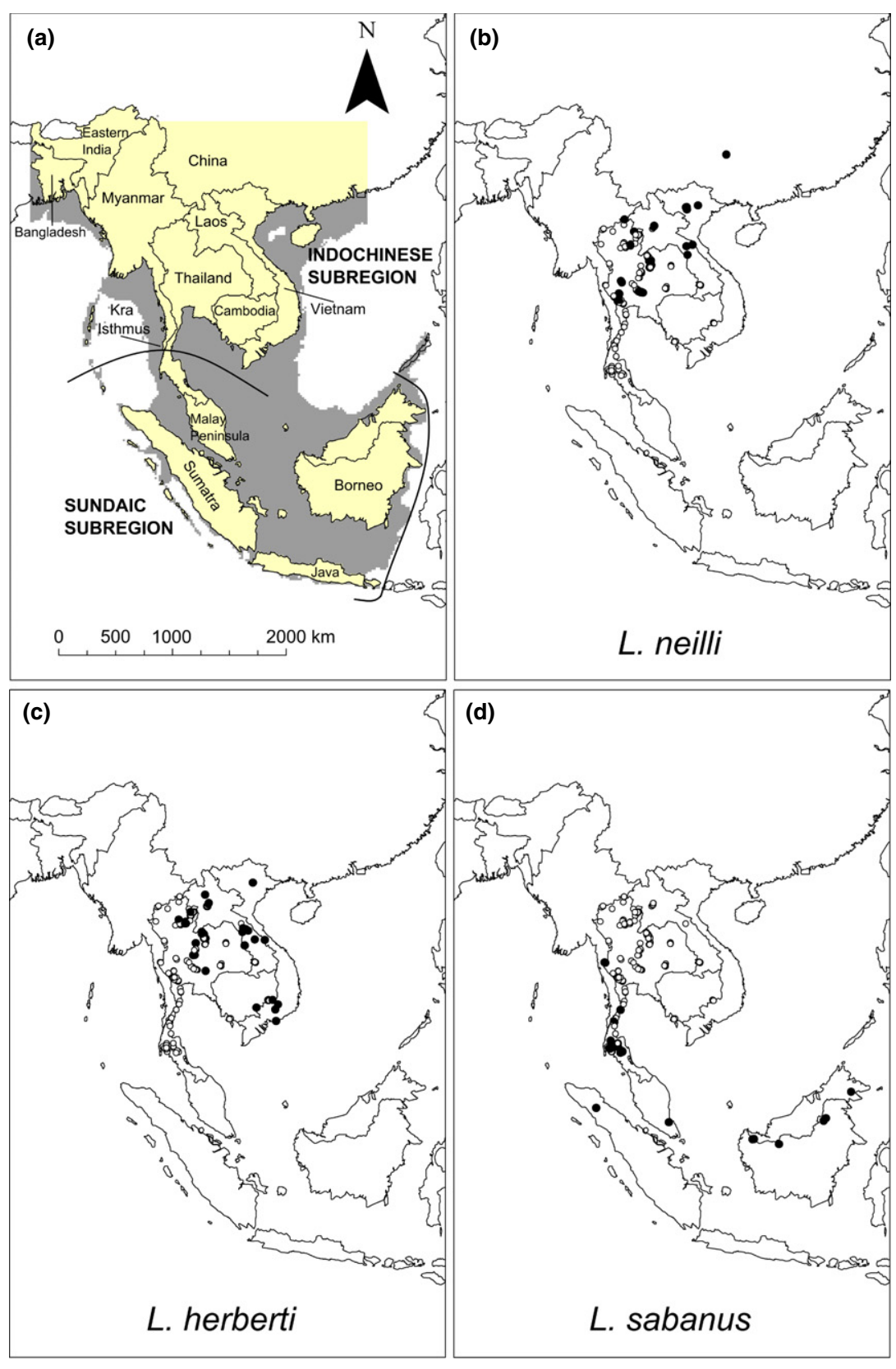

Figure 1 (a) The study area used to investigate the effect of past and future climate changes on the distribution of three Southeast Asian murids: the yellow area represents the projection zone of the potential distributions of the study species under current conditions and during the Last Interglacial (LIG). The grey area corresponds to the exposed Sunda shelf during the Last Glacial Maximum (LGM), when the sea level was $120 \mathrm{~m}$ below the current level (sea level representation from WorldClim; Hijmans et al., 2005; http:// www.worldclim.org). The Kra Isthmus represents the approximate northern limit of the Sundaic region. (b, c, d) Presenceabsence (black/white dots, respectively) data for the three study species, Leopoldamys neilli, L. herberti and L. sabanus.

\section{Species distribution modelling}

We built SDMs using present-day environmental variables before projecting the best models to past (hindcasting) and future (forecasting) climate scenarios. We started by carrying out a principal components analysis (PCA) with all WorldClim variables under present-day conditions, to choose a subset of environmental variables that explained the most variability in environmental gradients in the study region. This variable selection was carried out independently of the presence-absence data, in order to select environmental variables that represented meaningful gradients across the study region. The first three PCA axes explained $98 \%$ of the variance in the 19 bioclimatic variables used as predictors. We examined further the variables that contributed the most to these three axes and eliminated those that were highly correlated between them (Pearson's $r>0.8$ ). This left the following list of predictors: temperature seasonality (BIO4), annual precipitation (BIO12), precipitation of the warmest quarter (BIO18) and precipitation of the coldest quarter (BIO19). The functional responses of the study species to these four environmental predictors and the variations of these bioclimatic variables during the LIG and the LGM are depicted in Appendix S2.

We then ran a variety of models in the R 3.0.1 statistical package (R Core Team, 2013) to predict the current distribution of the three species using the four environmental predictors. We used seven different statistical models to include variability between strategies within an ensemble forecasting framework (Araújo \& New, 2007). These models included 
regression-like techniques [generalized linear regression (GLM) and generalized additive models (GAM) (MGCV package)], tree-like techniques [classification trees (CART) (RPART package) and boosted regression trees (BRT) (GBM package)] and presence-only methods. Two of the presenceonly methods [DOMAIN and BIOCLIM (DISmo package)] rely on statistical characterizations of the environment occupied by the species, while Maxent 3.3.3k (downloaded from http://www.cs.princeton.edu/ schapire/maxent/ and run using the DISmo package) relies on maximum entropy.

We assessed the model performance by calculating classification errors for each model using the area under the receiver operating characteristic curve (AUC), sensitivity, specificity and true skill statistic (TSS; sensitivity + specificity -1 ) and a cross-validation strategy. We used $90 \%$ of the data to calibrate the models and $10 \%$ to calculate performance measures. This provided a reasonable trade-off between having enough testing points and not eliminating a number of occurrences from the calibration set that would be limiting for model calibration, particularly when there was a scant number of occurrences. All performance measures (including those for MAXENT) were calculated within R. AUC is an overall performance measure that takes both the presence and absence classification errors into account (Fielding \& Bell, 1997). Sensitivity represents the success rate for classifying presences, whereas specificity indicates absence classification success (Fielding \& Bell, 1997). While AUC is threshold-independent, sensitivity and specificity require a fixed threshold on the predicted probability of occurrence above which all sites are predicted as presences and below which absences are predicted. We used the threshold that maximized sensitivity + specificity (maximizing sum threshold, MST), as recommended in previous studies (Liu et al., 2005a; Jimenez-Valverde \& Lobo, 2007).

Finally, models with high classification rates (AUC $>0.8$ and TSS > 0.6) were used to draw up consensus maps for each species under current, past and future climatic conditions, while other models were discarded. We calculated mean, median and the first PCA axis in a PCA of predicted values for all the best models (Marmion et al., 2009). These different consensus strategies generated similar distributions, so we only present the median results.

\section{RESULTS}

The models varied greatly in their classification performance but there were three to five models for each species that had an AUC $>0.8$ and TSS $>0.6$ (Table 1) and were therefore used for drawing up the consensus distribution maps.

\section{Current and past projections}

Besides central and northern Thailand, large areas of presence were predicted for L. neilli in Laos, Vietnam, central

Table 1 Classification performance measures resulting from fitting the distribution models of three Southeast Asian murids under current climatic conditions with $90 \%$ of the data, and calculating the classification error with the other $10 \%$. For MAXENT, the data were subsampled in $\mathrm{R}$, exported to MAXENT, and then the results re-imported into $\mathrm{R}$ in order to calculate the statistics using the same strategy as for the other models. Models with high classification rates [area under the receiver operating characteristic curve (AUC) $>0.8$ and true skill statistic (TSS) $>0.6]$ are in bold. MST, maximizing sum threshold.

\begin{tabular}{llcccc}
\hline Species & Model & AUC & TSS & Sensitivity (MST) & Specificity (MST) \\
\hline Leopoldamys neilli & BIOCLIM & $0.703 \pm 0.018$ & $0.5 \pm 0.064$ & $0.7 \pm 0.104$ & $0.8 \pm 0.02$ \\
& BRT & $\mathbf{0 . 8 5 6} \pm \mathbf{0 . 0 0 9}$ & $\mathbf{0 . 7 1} \pm \mathbf{0 . 0 3 1}$ & $\mathbf{0 . 9 6 7} \pm \mathbf{0 . 0 1 0}$ & $\mathbf{0 . 7 4 3} \pm \mathbf{0 . 0 2 5}$ \\
& CART & $0.793 \pm 0.019$ & $0.569 \pm 0.09$ & $0.75 \pm 0.092$ & $0.819 \pm 0.04$ \\
DOMAIN & $0.693 \pm 0.013$ & $0.469 \pm 0.056$ & $0.85 \pm 0.041$ & $0.619 \pm 0.075$ \\
& GAM & $\mathbf{0 . 8} \pm \mathbf{0 . 0 1 6}$ & $\mathbf{0 . 6 4 4} \pm \mathbf{0 . 0 3 8}$ & $\mathbf{0 . 8 5} \pm \mathbf{0 . 0 4 1}$ & $\mathbf{0 . 7 9 3} \pm \mathbf{0 . 0 3 2}$ \\
& GLM & $\mathbf{0 8 2 3} \pm \mathbf{0 . 0 1 9}$ & $\mathbf{0 . 6 6 2} \pm \mathbf{0 . 0 4 5}$ & $\mathbf{0 . 9} \pm \mathbf{0 . 0 2 5}$ & $\mathbf{0 . 7 6 2} \pm \mathbf{0 . 0 3 9}$ \\
& Maxent & $\mathbf{0 . 8 9 4} \pm \mathbf{0 . 0 1 1}$ & $\mathbf{0 . 7 9} \pm \mathbf{0 . 0 2}$ & $\mathbf{0 . 9 8 3} \pm \mathbf{0 . 0 0 5}$ & $\mathbf{0 . 8 0 6} \pm \mathbf{0 . 0 1 7}$ \\
Leopoldamys herberti & BIOCLIM & $0.711 \pm 0.011$ & $0.472 \pm 0.04$ & $0.733 \pm 0.089$ & $0.667 \pm 0.032$ \\
& BRT & $0.776 \pm 0.014$ & $0.622 \pm 0.036$ & $0.867 \pm 0.04$ & $0.694 \pm 0.022$ \\
& CART & $0.737 \pm 0.016$ & $0.439 \pm 0.105$ & $0.65 \pm 0.099$ & $0.706 \pm 0.052$ \\
& DOMAIN & $0.638 \pm 0.009$ & $0.267 \pm 0.076$ & $0.817 \pm 0.087$ & $0.483 \pm 0.076$ \\
& GAM & $\mathbf{0 . 8 0 6} \pm \mathbf{0 . 0 1 7}$ & $\mathbf{0 . 6 6 7} \pm \mathbf{0 . 0 5 2}$ & $\mathbf{0 . 9 1 7} \pm \mathbf{0 . 0 2 2}$ & $\mathbf{0 . 7 3 9} \pm \mathbf{0 . 0 3 1}$ \\
& GLM & $\mathbf{0 . 8 3 7} \pm \mathbf{0 . 0 1 6}$ & $\mathbf{0 . 7 5} \pm \mathbf{0 . 0 3 4}$ & $\mathbf{0 . 9 1 7} \pm \mathbf{0 . 0 2 2}$ & $\mathbf{0 . 7 8 9} \pm \mathbf{0 . 0 2 1}$ \\
& Maxent & $\mathbf{0 . 8 6 7} \pm \mathbf{0 . 0 1 6}$ & $\mathbf{0 . 7 4 4} \pm \mathbf{0 . 0 5}$ & $\mathbf{0 . 9 6 7} \pm \mathbf{0 . 0 1}$ & $\mathbf{0 . 7 8 3} \pm \mathbf{0 . 0 3 5}$ \\
& BIOCLIM & $0.746 \pm 0.024$ & $0.54 \pm 0.096$ & $0.675 \pm 0.112$ & $0.865 \pm 0.013$ \\
Leopoldamys sabanus & BRT & $\mathbf{0 . 9 6} \pm \mathbf{0 . 0 0 3}$ & $\mathbf{0 . 9 3 5} \pm \mathbf{0 . 0 0 8}$ & $\mathbf{1 . 0 0 0} \pm \mathbf{0 . 0 0 0}$ & $\mathbf{0 . 9 3 5} \pm \mathbf{0 . 0 0 8}$ \\
& CART & $0.775 \pm 0.03$ & $0.525 \pm 0.142$ & $0.600 \pm 0.147$ & $0.925 \pm 0.01$ \\
& DOMAIN & $\mathbf{0 . 8 5 2} \pm \mathbf{0 . 0 1 3}$ & $\mathbf{0 . 8 0 5} \pm \mathbf{0 . 0 1 9}$ & $\mathbf{1 . 0 0 0} \pm \mathbf{0 . 0 0 0}$ & $\mathbf{0 . 8 0 5} \pm \mathbf{0 . 0 1 9}$ \\
& GAM & $\mathbf{0 . 9 4 2} \pm \mathbf{0 . 0 0 4}$ & $\mathbf{0 . 8 6 5} \pm \mathbf{0 . 0 2 4}$ & $\mathbf{0 . 9 7 5} \pm \mathbf{0 . 0 1 2}$ & $\mathbf{0 . 8 9} \pm \mathbf{0 . 0 1 8}$ \\
& GLM & $\mathbf{0 . 9 6 2} \pm \mathbf{0 . 0 0 3}$ & $\mathbf{0 . 9 3} \pm \mathbf{0 . 0 0 9}$ & $\mathbf{1 . 0 0 0} \pm \mathbf{0 . 0 0 0}$ & $\mathbf{0 . 9 3} \pm \mathbf{0 . 0 0 8}$ \\
& Maxent & $\mathbf{0 . 9 5} \pm \mathbf{0 . 0 0 4}$ & $\mathbf{0 . 9} \pm \mathbf{0 . 0 1 7}$ & $\mathbf{1 . 0 0 0} \pm \mathbf{0 . 0 0 0}$ & $\mathbf{0 . 9} \pm \mathbf{0 . 0 1 7}$ \\
\hline
\end{tabular}

BRT, boosted regression trees; CART, classification trees; GAM, generalized additive models; GLM, generalized linear regression. 

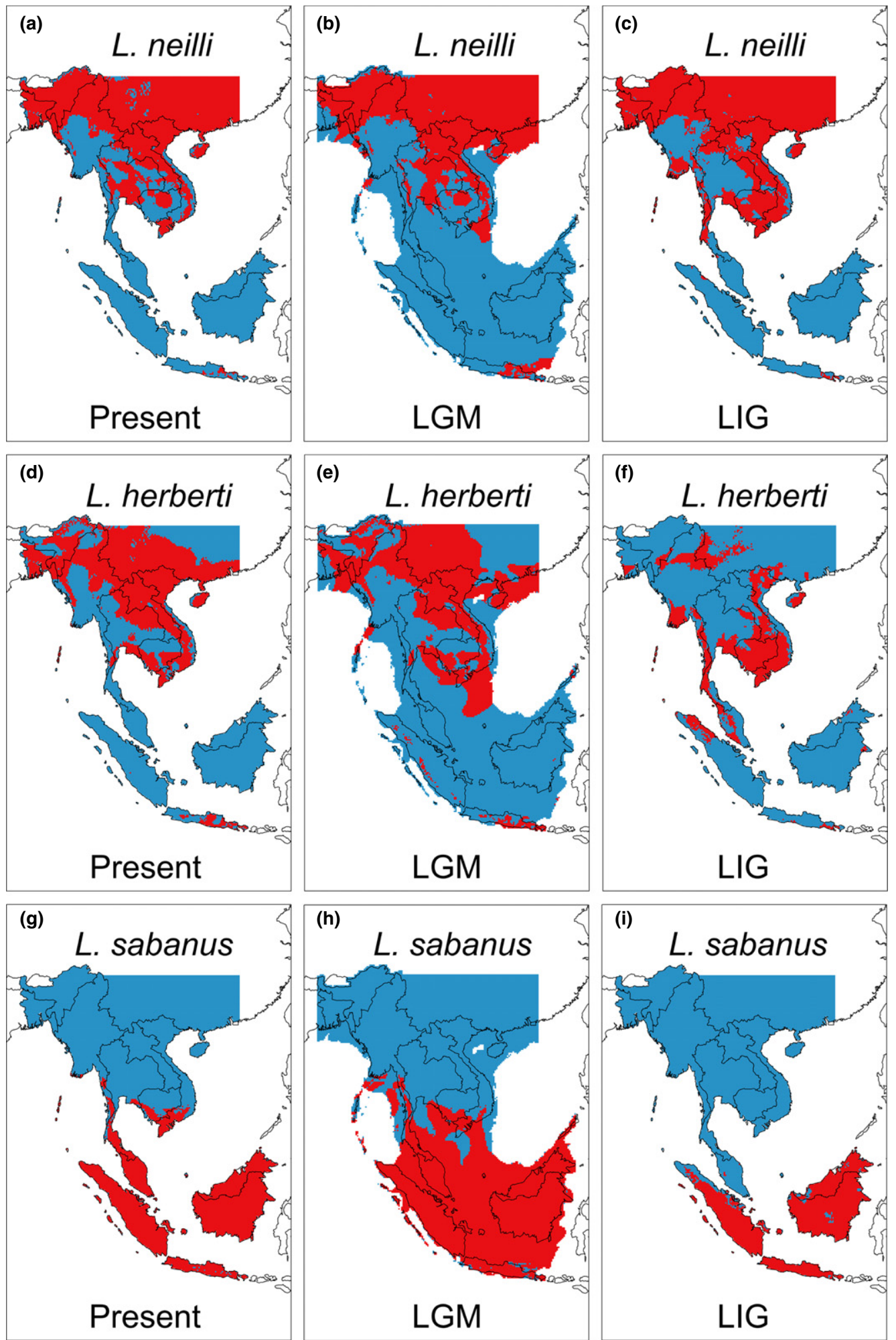

Figure 2 Consensus maps among the best performing models of the predicted distributions of three Southeast Asian murids (in red): Leopoldamys neilli ( $\mathrm{a}, \mathrm{b}, \mathrm{c})$, L. herberti ( $\mathrm{d}, \mathrm{e}, \mathrm{f}$ ) and L. sabanus ( $\mathrm{g}, \mathrm{h}, \mathrm{i})$ under current, Last Glacial Maximum (LGM) and Last Interglacial (LIG) conditions. The representation of sea level during the LGM is from WorldClim (Hijmans et al., 2005; http:// www.worldclim.org). 
Cambodia, southern China, northern Myanmar and eastern India under current conditions (Fig. 2a). The consensus distribution under LGM conditions for this species was mostly similar to its present-day distribution (Fig. 2b, Appendix S3). Moreover, a small potentially suitable area for L. neilli was predicted during the LGM on the exposed Sunda shelf, in the northern portion of the current South China Sea. The projection at the LIG predicted a range contraction for L. neilli in central Thailand and a range expansion in the southern part of the Indochinese region compared with its potential current and LGM distributions (Fig. 2c, Appendix S3).

For L. herberti, large continuous tracts of potential occurrence were predicted under current conditions in northern Thailand, Laos, northern Vietnam, southern China, northern and eastern Myanmar and eastern India, as well as in central Thailand, southern Cambodia and southern Vietnam (Fig. 2d). No major changes were observed between the potential distributions of this species under current and LGM climatic conditions, with the exception of small range expansions in some parts of the emerged Sunda shelf during the LGM (Fig. 2e, Appendix S3). However, a marked contraction of climatically suitable area for L. herberti in the northern part of the Indochinese region during the LIG was observed while it expanded southwards (Fig. 2f, Appendix S3).

The current potential range of L. sabanus included southern Thailand and the Malay Peninsula, in addition to the islands of Sumatra, Java and Borneo (Fig. 2g). Small regions of climatically suitable habitat were also predicted for this species in western Thailand, southern Cambodia and Vietnam. The predicted distribution of $L$. sabanus during the LGM also encompassed the Thai-Malay Peninsula, some areas of southern Cambodia and Vietnam as well as a large part of the exposed Sundaland (Fig. 2h,i, Appendix S3). During the LIG, climatically suitable areas for L. sabanus were restricted to Borneo, Sumatra and Java.

\section{Climate change scenarios for $\mathbf{2 0 8 0}$}

Overall, an expansion of the potential distributional range of L. neilli was predicted for many areas of the Indochinese subregion under the A1B scenario for 2080 (Fig. 3a). However, its predicted distribution under the B2A scenario showed more conservative expansions and a range reduction in areas of central Thailand, northern Laos and south-western China (Fig. 3b).

For L. herberti, the main distributional changes under the A1B scenario were predicted in northern and central Thailand, where the species was more likely be found in 2080 (Fig. 3c). In contrast, under the B2A scenario, the predicted distributional range of $L$. herberti decreased in northern and north-eastern Thailand and south-western China, while it slightly increased in southern China (Fig. 3d).

Neither A1B nor B2A scenarios predicted any future distributional change for L. sabanus in the Sundaic subregion. Only minor changes were predicted in the Indochinese subregion, close to the northern limit of its potential range (Fig. 3e,f).

\section{DISCUSSION}

\section{Current distribution of the three Leopoldamys species}

Our maps contribute to a better understanding of the potential current range of the study species and provide a working hypothesis for further evaluation in the field. Our results confirmed the Indochinese distribution of L. herberti, while L. sabanus was confined to the Sundaic subregion, with the exception of a patch of suitable habitat in southern Vietnam and southern Cambodia, where the two species could occur in sympatry. However, no genetically identified L. sabanus specimens have ever been recorded in this area so the presence of $L$. sabanus in the south-eastern part of the Indochinese region remains hypothetical; dispersal limitations as well as possible competition with other species could explain its absence there.

The potential distribution of $L$. neilli was quite similar to that of $L$. herberti but extended further in eastern India and southern China. However, the distribution of L. neilli is dependent on the presence of limestone karsts. Therefore the exact distribution of this species would probably be more fragmented than indicated by our distribution maps, and climatically suitable areas predicted in our study area should be viewed with caution for this species and reviewed in light of the availability of karsts in different areas. Large tracts of climatically suitable habitat for $L$. neilli and L. herberti were predicted in Bangladesh, eastern India and northern Myanmar. No genetic data on Leopoldamys specimens from these areas are currently available, but the presence of $L$. edwardsi in these regions has been reported in the literature (Musser \& Carleton, 2005). Further genetic studies in the Bangladesh, India and Myanmar regions mentioned above could therefore be useful for fine-tuning the distribution maps presented here. A few patches of climatically suitable habitat for L. herberti and $L$. neilli were also predicted on Java, in the Sundaic region. However, these species have never been recorded on Java or neighbouring islands, and their presence in this region would be highly unlikely.

\section{Influence of the Pleistocene climatic fluctuations on the distribution of Leopoldamys species}

Climatic variables such as temperature and precipitation are major determinants of vegetation types, and major changes in vegetation cover in Southeast Asia occurred during the Pleistocene as a result of climatic oscillations. These vegetation changes may have played a major role in shaping the phylogeographical structure of Southeast Asian fauna (Luo et al., 2004; Fuchs et al., 2008; Lim \& Sheldon, 2011; Morgan et al., 2011). However, there is no firm consensus on the Quaternary distribution of vegetation types in this region. During the Pleistocene glacial periods, it has been suggested 


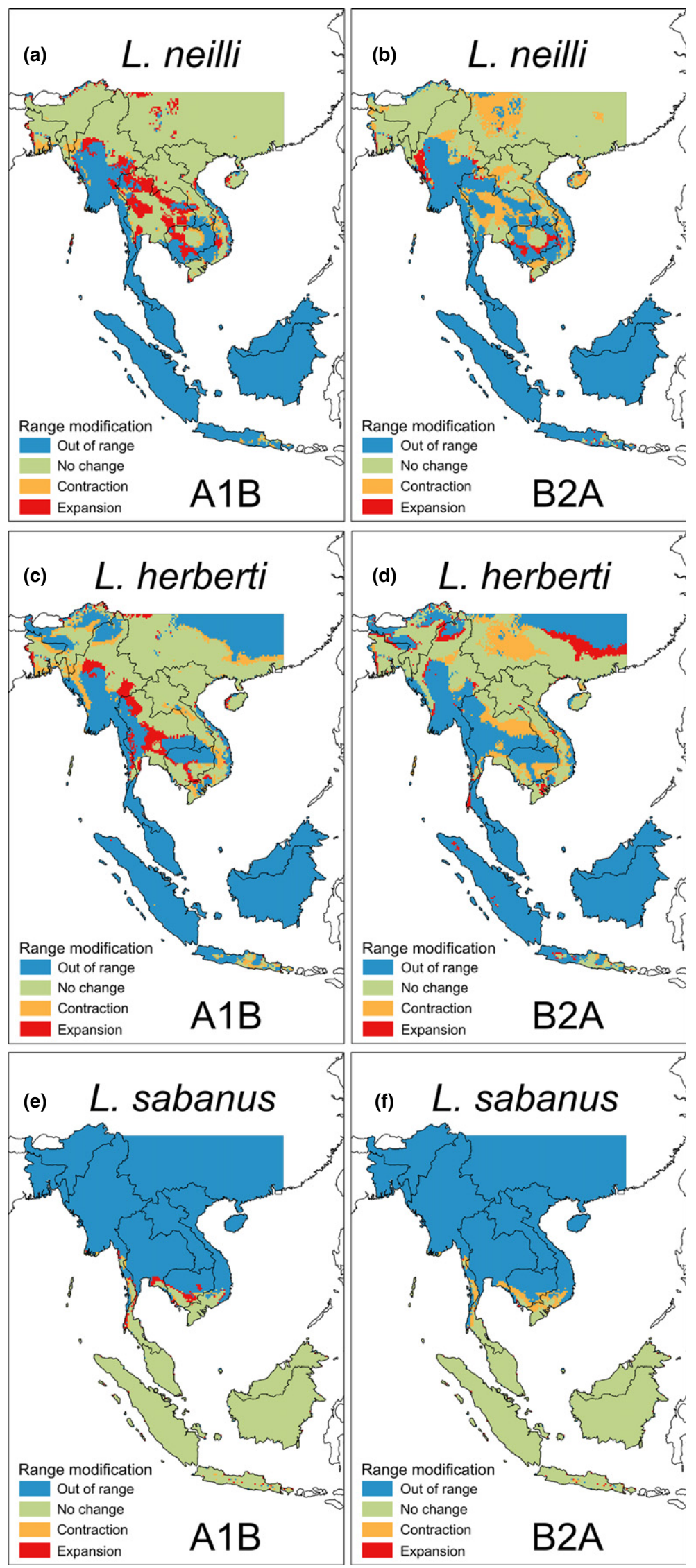

Figure 3 Consensus distribution maps among the best performing models of the predicted future range modifications of three Southeast Asian murids: Leopoldamys neilli (a, b), L. herberti (c, d), L. sabanus (e, f) under $\mathrm{A} 1 \mathrm{~B}$ and $\mathrm{B} 2 \mathrm{~A}$ climate change scenarios for 2080 . 
that Southeast Asian tropical rain forests retracted with only a few subsisting refugia, and that they were replaced by seasonal forests and savanna (Hope et al., 2004; Bird et al., 2005; Wurster et al., 2010). Alternatively, some studies have indicated that during the LGM a large and continuous tract of tropical lowland rain forest persisted on the Sundaland (Cannon et al., 2009; Wang et al., 2009).

As a forest-dwelling rodent living in evergreen and montane forests of the Indochinese region, the distribution of $L$. herberti could have been influenced by Pleistocene changes in vegetation cover. However, according to our models based on climatic variables, the potential LGM distributional range of this species was unexpectedly similar to its present-day distribution. More surprisingly, our models revealed a substantial range contraction for L. herberti during the LIG in northern Indochina, while its distribution expanded in southern Indochina. Therefore, $L$. herberti populations could have been isolated in these northern and southern Indochinese refugia during the LIG. This interglacial fragmentation could have been responsible for the southern (L1a) and northern (L1b) Indochinese lineages observed within L. herberti (Balakirev et al., 2013).

Range expansion in southern Indochina during the LIG was also observed for L. neilli in our model projections but, in contrast to L. herberti, L. neilli did not seem to experience any range contraction in northern Indochina from the LIG to present day. However, the predicted LIG distribution of $L$. neilli in Thailand was much more reduced than today and during the LGM, which may have contributed to the high genealogical divergence observed among $L$. neilli lineages in Thailand (Latinne et al., 2011, 2012).

Our study of the potential distribution of L. sabanus clearly suggests that suitable habitats for this species subsisted on each Sunda island and the Thai-Malay Peninsula during the LGM. Gorog et al. (2004) reached similar conclusions and found a lack of phylogeographical structure for $L$. sabanus in Borneo, indicating that either the species survived in a single Bornean refugium from which it subsequently recolonized the rest of the island, or it occupied a large portion of Borneo during the LGM. Our models favour the latter hypothesis and also indicate that the exposed Sunda shelf during the LGM was a climatically suitable area for $L$. sabanus. These results support those of Cannon et al. (2009), who argue that rain forests would have been at their maximum on the Sunda shelf during the LGM. However, according to available genetic data, extensive migration of $L$. sabanus among the mainland and the Sunda islands did not seem to occur during the LGM. Three allopatric phylogenetic lineages corresponding to the Thai-Malay Peninsula, Borneo and Sumatra were observed within L. sabanus and their divergence largely pre-dated the LGM (Gorog et al., 2004). Two factors may explain this apparent lack of migration of L. sabanus across the Sunda shelf when our models indicated that the region was climatically suitable for this species. First, the existence of a north-south savanna corridor that may have acted as a dispersal barrier for forest-dwelling species has been suggested (Heaney, 1991; Penny, 2001; Bird et al., 2005; Wurster et al., 2010), although this has been refuted in other studies (Cannon et al., 2009; Wang et al., 2009; Slik et al., 2011). Second, the influence of abiotic factors such as soil conditions that may have limited plant growth has also been proposed to explain the absence or low level of crossshelf migration observed for numerous taxa in the Sundaic region (Lim \& Sheldon, 2011; Slik et al., 2011).

In an attempt to explain our results that contradict the well-established hypothesis that the LIG distribution of Southeast Asian forest-dwelling species was similar to their present-day distribution while these species were confined to small refugia during the LGM, we explored the past fluctuations of the four bioclimatic variables used in our models (Appendix S2). The most striking variation was observed for temperature seasonality (BIO4), which was consistently increased in Southeast Asia during the LIG compared with current conditions, while it did not vary greatly during the LGM. The three other bioclimatic predictors varied more heterogeneously in our study area. We noticed a stronger decrease in the precipitation of the coldest quarter of the year (BIO19) during the LIG than during the LGM in the Indochinese region, while the precipitation of the warmest quarter (BIO18) increased in southern Indochina and in the Sundaic region during the LIG. These increased seasonal contrasts of temperature and precipitation in Asia during the LIG were the result of higher insolation received during the boreal summer (Wang et al., 2008; Nikolova et al., 2013).

The seasonality of both temperature and precipitation is a major determinant of vegetation distribution and richness in Asia (Fang et al., 1996; Sang, 2009; Chiu et al., 2012) and its variation led to a modification of the relative abundance of $\mathrm{C}_{3}$ and $\mathrm{C}_{4}$ plants during the Pleistocene (Liu et al., 2005b; Yang et al., 2012). Therefore, as a result of this increased climatic seasonality during the LIG compared with the current or LGM climatic conditions, important changes in the vegetation cover may have occurred at that time and caused the range modifications predicted for $L$. herberti and, to a lesser extent, for L. neilli and L. sabanus during the LIG. These changes in environmental conditions affected some Leopoldamys species more severely than others because of their specific responses to each of these environmental drivers (Appendix S2).

Fossil records could be an interesting tool for testing the validity of our models. Numerous fossil teeth attributed to $L$. sabanus and dated from the middle to late Pleistocene have been discovered in Southeast Asia (Medway, 1977; Chaimanee, 1998; Storm et al., 2005; Bacon et al., 2006) but only a few of them have been given an absolute age. Two Indochinese sites, Snake Cave in north-eastern Thailand (one fossiliferous level older than $160 \mathrm{ka}$; Esposito et al., 2002) and Ma U'Oi Cave in northern Vietnam (two fossiliferous levels dated to $193 \pm 17 \mathrm{ka}$ and $49 \pm 4 \mathrm{ka}$; Bacon et al., 2006), do not correspond with the periods studied (LIG and LGM) but have been attributed to other Pleistocene glacial periods. Their usefulness for validating our predictions is thus very 
limited. Moreover, although these teeth probably belong to Leopoldamys, their identification at the species level remains uncertain because of the recent taxonomic changes introduced within that genus and described in the Introduction. These fossil teeth need to be re-examined and identified on the basis of the latest taxonomic revisions of the genus Leopoldamys (Musser et al., 2006). Our past potential distribution maps predicted the presence of both $L$. herberti and $L$. neilli in northern Thailand and northern Vietnam during the LGM and are concordant with the available fossil data if we consider their LGM distribution as representative of their distribution during other Pleistocene glacial periods and that the fossil teeth from Chaimanee (1998) and Bacon et al. (2006) belong to a Leopoldamys species other than L. sabanus. Leopoldamys sabanus teeth have also been identified in eastern Java and are representative of the Punung fauna of early LIG age (between $118 \pm 3 \mathrm{ka}$ and $128 \pm 15 \mathrm{ka}$ ) (Storm et al., 2005; Westaway et al., 2007), thus corroborating our predicted LIG distribution for L. sabanus.

\section{Impact of future climate changes on Leopoldamys species}

Although the two future climate change scenarios used in this study showed contrasting results, large areas of predicted presence will subsist in the future for the three Leopoldamys species under both scenarios. The A1B scenario, which is now considered more plausible than the B2A scenario (Kriticos et al., 2012), predicted a range expansion in several areas for the three species. However, the subsistence of these species will depend on the availability and long-term maintenance of suitable habitats: limestone karsts for $L$. neilli and forests for $L$. herberti and L. sabanus. These habitats are highly threatened and both the annual limestone quarrying rate and the relative deforestation rate are higher in Southeast Asia than in other tropical regions of the world (Achard et al., 2002; Clements et al., 2006). Therefore, habitat loss as a result of direct anthropogenic causes rather than climate change appears to be the major threat these three species will face in the future. However, climate change may also negatively impact tropical tree growth and consequently affect the future survival of rain forests and their fauna (Feeley et al., 2007).

\section{CONCLUSIONS}

Overall, our model predictions for L. neilli, L. herberti and $L$. sabanus contradict the well-established hypothesis that Southeast Asian forest-dwelling species were confined to small refugia during Pleistocene glacial periods. Moreover, our model results contribute to a growing body of literature suggesting that the distribution of several East and Southeast Asian taxa were in their refugial state during Pleistocene interglacial periods rather than during glacial periods (Dai et al., 2011; Zhao et al., 2012; Peterson \& Ammann, 2013; Wang et al., 2013). The LIG has thus played a more important role than the LGM in isolating populations of these taxa and shaping their phylogeographical patterns. We hypothesize that this could be because of the important vegetation changes that may have occurred at that time as a result of the increased seasonality of both temperature and precipitations observed during the LIG.

Our study revealed a southward range expansion of $L$. herberti and L. neilli during the LIG and the probable importance of southern Indochina as providing refugia for $L$. herberti during Pleistocene climatic fluctuations. In contrast to the mountain ranges of northern Indochina, where L. herberti could also have subsisted during the LIG, southern Indochina has never been identified as potential Pleistocene refugia for forest-dwelling species in Southeast Asia. This region may host particular phylogeographical lineages of several forest-dwelling taxa, as observed for $L$. herberti, and deserves the attention of future phylogeographical studies in Indochina.

\section{ACKNOWLEDGEMENTS}

We thank all our collaborators who made the sample collection possible, and especially Boonchai Tontan, Sathaporn Jittapalapong, Kittipong Chaisiri, Prateep Rojanadilok, Krairat Eiamampai and Kriangsak Sribuarod. We are grateful to Ken Aplin, Konstans Wells and Maklarin Lakim for their samples, and to Marie Pagès for providing us with unpublished sequences of Leopoldamys. We also thank the University of Michigan Museum of Zoology for providing us with detailed locality information for several Leopoldamys specimens. This work was supported by a Belgian FRS-FNRS fellowship to A.L. (mandat 'aspirant') and to J.R.M. (mandat 'Maître de recherches') and financial grants from the Belgian FRS-FNRS ['crédits pour brefs séjours à l'étranger' to A.L. and J.R.M. and credits from the 'Fonds de la Recherche Fondamentale Collective (FRFC)' to J.R.M.], the University of Liège and the Communauté française de Belgique. A.L. was funded by a Marie Curie COFUND postdoctoral fellowship when writing this paper. This study is part of the 'CERoPath project', ANR Biodiversity ANR07 BDIV012, and the 'BiodivHealthSEA project', ANR CP\&ES11 CPEL002, funded by the French National Agency for Research. This paper is contribution number 3452 of the Virginia Institute of Marine Science, College of William \& Mary.

\section{REFERENCES}

Achard, F., Eva, H.D., Stibig, H.J., Mayaux, P., Gallego, J., Richards, T. \& Malingreau, J.P. (2002) Determination of deforestation rates of the world's humid tropical forests. Science, 297, 999-1002.

Araújo, M.B. \& New, M. (2007) Ensemble forecasting of species distributions. Trends in Ecology and Evolution, 22, 42-47.

Bacon, A.M., Demeter, F., Rousse, S., Long, V.T., Duringer, P., Antoine, P.O., Thuy, N.K., Mai, B.T., Huong, N.T.M., Dodo, Y., Matsumura, H., Schuster, M. \& Anezaki, T. (2006) New palaeontological assemblage, sedimentological 
and chronological data from the Pleistocene Ma U'Oi cave (northern Vietnam). Palaeogeography, Palaeoclimatology, Palaeoecology, 230, 280-298.

Balakirev, A.E., Abramov, A.V. \& Rozhnov, V.V. (2013) Revision of the genus Leopoldamys (Rodentia, Muridae) as inferred from morphological and molecular data, with a special emphasis on the species composition in continental Indochina. Zootaxa, 3640, 521-549.

Bertelsmeier, C., Guénard, B. \& Courchamp, F. (2013) Climate change may boost the invasion of the Asian needle ant. PLoS ONE, 8, e75438.

Bird, M.I., Taylor, D. \& Hunt, C. (2005) Palaeoenvironments of insular Southeast Asia during the Last Glacial Period: a savanna corridor in Sundaland? Quaternary Science Reviews, 24, 2228-2242.

Brandon-Jones, D. (1996) The Asian Colobinae (Mammalia: Cercopithecidae) as indicators of Quaternary climatic change. Biological Journal of the Linnean Society, 59, 327350.

Butler, C.J., Wheeler, E.A. \& Stabler, L.B. (2012) Distribution of the threatened lace hedgehog cactus (Echinocereus reichenbachii) under various climate change scenarios. The Journal of the Torrey Botanical Society, 139, 46-55.

Cannon, C.H., Morley, R.J. \& Bush, A.B.G. (2009) The current refugial rainforests of Sundaland are unrepresentative of their biogeographic past and highly vulnerable to disturbance. Proceedings of the National Academy of Sciences USA, 106, 11188-11193.

Chaimanee, Y. (1998) Plio-Pleistocene rodents of Thailand. Thai Studies in Biodiversity, 3, 1-303.

Chang, G. \& Zhang, Z. (2011) Differences in hoarding behaviors among six sympatric rodent species on seeds of oil tea (Camellia oleifera) in Southwest China. Acta Oecologica, 37, 165-169.

Chiu, C.-A., Lin, P.-H., Hsu, C.-K. \& Shen, Z.-H. (2012) A novel thermal index improves prediction of vegetation zones: associating temperature sum with thermal seasonality. Ecological Indicators, 23, 668-674.

Clements, R., Sodhi, N.S., Schilthuizen, M. \& Ng, P.K.L. (2006) Limestone karsts of southeast Asia: imperiled arks of biodiversity. BioScience, 56, 733-742.

Dai, C., Zhao, N., Wang, W., Lin, C., Gao, B., Yang, X., Zhang, Z. \& Lei, F. (2011) Profound climatic effects on two East Asian black-throated tits (Ave: Aegithalidae), revealed by ecological niche models and phylogeographic analysis. PLoS ONE, 6, e29329.

Esposito, M., Reyss, J.-L., Chaimanee, Y. \& Jaeger, J.-J. (2002) U-series dating of fossil teeth and carbonates from Snake Cave, Thailand. Journal of Archaeological Science, 29, 341-349.

Fang, J.-Y., Ohsawa, M. \& Kira, T. (1996) Vertical vegetation zones along $30^{\circ} \mathrm{N}$ latitude in humid East Asia. Vegetatio, 126, 135-149.

Feeley, K.J., Wright, S.J., Supardi, M.N.N., Kassim, A.R. \& Davies, S.J. (2007) Decelerating growth in tropical forest trees. Ecology Letters, 10, 461-469.
Fielding, A.H. \& Bell, J.F. (1997) A review of methods for the assessment of prediction errors in conservation presence/ absence models. Environmental Conservation, 24, 38-49.

Fuchs, J., Ericson, P.G.P. \& Pasquet, E. (2008) Mitochondrial phylogeographic structure of the white-browed piculet (Sasia ochracea): cryptic genetic differentiation and endemism in Indochina. Journal of Biogeography, 35, 565-575.

Gorog, A.J., Sinaga, M.H. \& Engstrom, M.D. (2004) Vicariance or dispersal? Historical biogeography of three Sunda shelf murine rodents (Maxomys surifer, Leopoldamys sabanus and Maxomys whiteheadi). Biological Journal of the Linnean Society, 81, 91-109.

Haffer, J. (1997) Alternative models of vertebrate speciation in Amazonia: an overview. Biodiversity and Conservation, 6, 451-476.

Heaney, L.R. (1986) Biogeography of mammals in SE Asia: estimates of rates of colonization, extinction and speciation. Biological Journal of the Linnean Society, 28, 127-165.

Heaney, L.R. (1991) A synopsis of climatic and vegetational change in Southeast Asia. Climatic Change, 19, 53-61.

Hewitt, G.M. (2004) Genetic consequences of climatic oscillations in the Quaternary. Philosophical Transactions of the Royal Society B: Biological Sciences, 359, 183-195.

Hijmans, R.J., Cameron, S.E., Parra, J.L., Jones, P.G. \& Jarvis, A. (2005) Very high resolution interpolated climate surfaces for global land areas. International Journal of Climatology, 25, 1965-1978.

Hope, G., Kershaw, A.P., van der Kaars, S., Xiangjun, S., Liew, P.M., Heusser, L.E., Takahara, H., McGlone, M., Miyoshi, N. \& Moss, P.T. (2004) History of vegetation and habitat change in the Austral-Asian region. Quaternary International, 118, 103-126.

IPCC (2007) Fourth Assessment Report of the Intergovernmental Panel on Climate Change. Cambridge University Press, Cambridge, UK.

Jimenez-Valverde, A. \& Lobo, J.M. (2007) Threshold criteria for conversion of probability of species presence to eitheror presence-absence. Acta Oecologica, 31, 361-369.

Kotlík, P., Deffontaine, V., Mascheretti, S., Zima, J., Michaux, J.R. \& Searle, J.B. (2006) A northern glacial refugium for bank voles (Clethrionomys glareolus). Proceedings of the National Academy of Sciences USA, 103, 14860-14864.

Kriticos, D.J., Webber, B.L., Leriche, A., Ota, N., Macadam, I., Bathols, J. \& Scott, J.K. (2012) CliMond: global highresolution historical and future scenario climate surfaces for bioclimatic modelling. Methods in Ecology and Evolution, 3, 53-64.

Latinne, A., Waengsothorn, S., Herbreteau, V. \& Michaux, J.R. (2011) Evidence of complex phylogeographic structure for the threatened rodent Leopoldamys neilli, in Southeast Asia. Conservation Genetics, 12, 1495-1511.

Latinne, A., Waengsothorn, S., Rojanadilok, P., Eiamampai, K., Sribuarod, K. \& Michaux, J.R. (2012) Combined mitochondrial and nuclear markers revealed a deep vicariant history for Leopoldamys neilli, a cave-dwelling rodent of Thailand. PLoS ONE, 7, e47670. 
Latinne, A., Chaval, Y., Waengsothorn, S., Rojanadilok, P., Eiamampai, K., Sribuarod, K., Herbreteau, V., Morand, S. \& Michaux, J.R. (2013a) Is Leopoldamys neilli (Rodentia, Muridae) a synonym of Leopoldamys herberti? A reply to Balakirev et al. (2013). Zootaxa, 3731, 589-598.

Latinne, A., Waengsothorn, S., Rojanadilok, P., Eiamampai, K., Sribuarod, K. \& Michaux, J.R. (2013b) Diversity and endemism of Murinae rodents in Thai limestone karsts. Systematics and Biodiversity, 11, 323-344.

Lim, H.C. \& Sheldon, F.H. (2011) Multilocus analysis of the evolutionary dynamics of rainforest bird populations in Southeast Asia. Molecular Ecology, 20, 3414-3438.

Lim, H.C., Zou, F., Taylor, S.S., Marks, B.D., Moyle, R.G., Voelker, G. \& Sheldon, F.H. (2010) Phylogeny of magpierobins and shamas (Aves: Turdidae: Copsychus and Trichixos): implications for island biogeography in Southeast Asia. Journal of Biogeography, 37, 1894-1906.

Liu, C.R., Berry, P.M., Dawson, T.P. \& Pearson, R.G. (2005a) Selecting thresholds of occurrence in the prediction of species distributions. Ecography, 28, 385-393.

Liu, W., Huang, Y., An, Z., Clemens, S.C., Li, L., Prell, W.L. \& Ning, Y. (2005b) Summer monsoon intensity controls $\mathrm{C}_{4} / \mathrm{C}_{3}$ plant abundance during the last $35 \mathrm{ka}$ in the Chinese Loess Plateau: carbon isotope evidence from bulk organic matter and individual leaf waxes. Palaeogeography, Palaeoclimatology, Palaeoecology, 220, 243-254.

Lunde, D.P. \& Aplin, K. (2008) Leopoldamys neilli. IUCN Red List of Threatened Species. Version 2014.2. Available at: http://www.iucnredlist.org.

Lunde, D.P., Aplin, K., Ruedas, L.A. \& Molur, S. (2008) Leopoldamys sabanus. IUCN Red List of Threatened Species. Version 2014.2. Available at: http://www.iucnredlist.org.

Luo, S.-J., Kim, J.-H., Johnson, W.E. et al. (2004) Phylogeography and genetic ancestry of tigers Panthera tigris. PLoS Biology, 2, e442.

Marmion, M., Parviainen, M., Luoto, M., Heikkinen, R.K. \& Thuiller, W. (2009) Evaluation of consensus methods in predictive species distribution modelling. Diversity and Distributions, 15, 59-69.

Medway, L. (1977) The Niah excavations and an assessment of the impact of early man on mammals in Borneo. Asian Perspectives, 20, 51-69.

Michaux, J.R., Libois, R. \& Filippucci, M.G. (2005) So close and so different: comparative phylogeography of two small mammal species, the yellow-necked fieldmouse (Apodemus flavicollis) and the woodmouse (Apodemus sylvaticus) in the western Palearctic region. Heredity, 94, 52-63.

Morgan, K., O’Loughlin, S.M., Chen, B., Linton, Y.M., Thongwat, D., Somboon, P., Fong, M.Y., Butlin, R., Verity, R., Prakash, A., Htun, P.T., Hlaing, T., Nambanya, S., Socheat, D., Dinh, T.H. \& Walton, C. (2011) Comparative phylogeography reveals a shared impact of Pleistocene environmental change in shaping genetic diversity within nine Anopheles mosquito species across the Indo-Burma biodiversity hotspot. Molecular Ecology, 20, 4533-4549.
Musser, G.G. \& Carleton, M. (2005) Superfamily Muroidea. Mammal species of the world: a taxonomic and geographic reference (ed. by D.E. Wilson and D.M. Reeder), pp. 8941531. Johns Hopkins University Press, Baltimore, MD.

Musser, G.G., Lunde, D.P. \& Son, N.T. (2006) Description of a new genus and species of rodent (Murinae, Muridae, Rodentia) from the tower karst region of northeastern Vietnam. American Museum Novitates, 3517, 1-41.

Myers, N., Mittermeier, R.A., Mittermeier, C.G., da Fonseca, G.A.B. \& Kent, J. (2000) Biodiversity hotspots for conservation priorities. Nature, 403, 853-858.

Nikolova, I., Yin, Q., Berger, A., Singh, U.K. \& Karami, M.P. (2013) The last interglacial (Eemian) climate simulated by LOVECLIM and CCSM3. Climate of the Past, 9, 17891806.

Pagès, M., Chaval, Y., Herbreteau, V., Waengsothorn, S., Cosson, J.F., Hugot, J.P., Morand, S. \& Michaux, J. (2010) Revisiting the taxonomy of the Rattini tribe: a phylogenybased delimitation of species boundaries. BMC Evolutionary Biology, 10, 184.

Patou, M.L., Wilting, A., Gaubert, P., Esselstyn, J.A., Cruaud, C., Jennings, A.P., Fickel, J. \& Veron, G. (2010) Evolutionary history of the Paradoxurus palm civets: a new model for Asian biogeography. Journal of Biogeography, 37, 20772097.

Peltier, W.R. \& Fairbanks, R.G. (2006) Global glacial ice volume and Last Glacial Maximum duration from an extended Barbados sea level record. Quaternary Science Reviews, 25, 3322-3337.

Penny, D. (2001) A 40,000 year palynological record from north-east Thailand; implications for biogeography and palaeo-environmental reconstruction. Palaeogeography, Palaeoclimatology, Palaeoecology, 171, 97-128.

Peterson, A.T. \& Ammann, C.M. (2013) Global patterns of connectivity and isolation of populations of forest bird species in the late Pleistocene. Global Ecology and Biogeography, 22, 596-606.

Porretta, D., Mastrantonio, V., Bellini, R., Somboon, P. \& Urbanelli, S. (2012) Glacial history of a modern invader: phylogeography and species distribution modelling of the Asian Tiger mosquito Aedes albopictus. PLoS ONE, 7, e44515.

R Core Team (2013) R: a language and environment for statistical computing. R Foundation for Statistical Computing, Vienna, Austria.

Sang, W. (2009) Plant diversity patterns and their relationships with soil and climatic factors along an altitudinal gradient in the middle Tianshan Mountain area, Xinjiang, China. Ecological Research, 24, 303-314.

Shackleton, N.J., Sánchez-Goñi, M.F., Pailler, D. \& Lancelot, Y. (2003) Marine isotope substage $5 \mathrm{e}$ and the Eemian interglacial. Global and Planetary Change, 36, 151-155.

Slik, J.W.F., Aiba, S.I., Bastian, M. et al. (2011) Soils on exposed Sunda Shelf shaped biogeographic patterns in the equatorial forests of Southeast Asia. Proceedings of the National Academy of Sciences USA, 108, 12343-12347. 
Stewart, J.R., Lister, A.M., Barnes, I. \& Dalén, L. (2010) Refugia revisited: individualistic responses of species in space and time. Proceedings of the Royal Society B: Biological Sciences, 277, 661-671.

Storm, P., Aziz, F., de Vos, J., Kosasih, D., Baskoro, S., Ngaliman \& van den Hoek Ostende, L.W. (2005) Late Pleistocene Homo sapiens in a tropical rainforest fauna in East Java. Journal of Human Evolution, 49, 536-545.

Voris, H.K. (2000) Maps of Pleistocene sea levels in Southeast Asia: shorelines, river systems and time durations. Journal of Biogeography, 27, 1153-1167.

Wang, Y., Cheng, H., Edwards, R.L., Kong, X., Shao, X., Chen, S., Wu, J., Jiang, X., Wang, X. \& An, Z. (2008) Millennial- and orbital-scale changes in the East Asian monsoon over the past 224,000 years. Nature, 451, 1090-1093.

Wang, X., Sun, X., Wang, P. \& Stattegger, K. (2009) Vegetation on the Sunda Shelf, South China Sea, during the Last Glacial Maximum. Palaeogeography, Palaeoclimatology, Palaeoecology, 278, 88-97.

Wang, W., McKay, B.D., Dai, C., Zhao, N., Zhang, R., Qu, Y., Song, G., Li, S.-H., Liang, W., Yang, X., Pasquet, E. \& Lei, F. (2013) Glacial expansion and diversification of an East Asian montane bird, the green-backed tit (Parus monticolus). Journal of Biogeography, 40, 1156-1169.

Wells, K., Kalko, E.K.V., Lakim, M.B. \& Pfeiffer, M. (2007) Effects of rain forest logging on species richness and assemblage composition of small mammals in Southeast Asia. Journal of Biogeography, 34, 1087-1099.

Wells, K., Corlett, R.T., Lakim, M.B., Kalko, E.K.V. \& Pfeiffer, M. (2009) Seed consumption by small mammals from Borneo. Journal of Tropical Ecology, 25, 555-558.

Westaway, K.E., Morwood, M.J., Roberts, R.G., Rokus, A.D., Zhao, J.X., Storm, P., Aziz, F., van den Bergh, G., Hadi, P., Jatmiko \& de Vos, J. (2007) Age and biostratigraphic significance of the Punung Rainforest Fauna, East Java, Indonesia, and implications for Pongo and Homo. Journal of Human Evolution, 53, 709-717.

Woodruff, D.S. (2010) Biogeography and conservation in Southeast Asia: how 2.7 million years of repeated environmental fluctuations affect today's patterns and the future of the remaining refugial-phase biodiversity. Biodiversity and Conservation, 19, 919-941.

Wurster, C.M., Bird, M.I., Bull, I.D., Creed, F., Bryant, C., Dungait, J.A.J. \& Paz, V. (2010) Forest contraction in north equatorial Southeast Asia during the Last Glacial Period. Proceedings of the National Academy of Sciences USA, 107, 15508-15511.

Yang, S., Ding, Z., Wang, X., Tang, Z. \& Gu, Z. (2012) Negative $\delta^{18} \mathrm{O}-\delta^{13} \mathrm{C}$ relationship of pedogenic carbonate from northern China indicates a strong response of $\mathrm{C}_{3} / \mathrm{C}_{4}$ biomass to the seasonality of Asian monsoon precipitation. Palaeogeography, Palaeoclimatology, Palaeoecology, 317-318, 32-40.

Zhao, N., Dai, C., Wang, W., Zhang, R., Qu, Y., Song, G., Chen, K., Yang, X., Zou, F. \& Lei, F. (2012) Pleistocene climate changes shaped the divergence and demography of Asian populations of the great tit Parus major: evidence from phylogeographic analysis and ecological niche models. Journal of Avian Biology, 43, 297-310.

Zheng, S. (1993) Quaternary rodents of Sichuan-Guizhou area. Science Press, Beijing, China.

\section{SUPPORTING INFORMATION}

Additional Supporting Information may be found in the online version of this article:

Appendix S1 GenBank accession numbers and phylogenetic tree including all the samples used in this study.

Appendix S2 Responses of the three study species to the four selected bioclimatic predictors and variations of these bioclimatic variables during the LIG and the LGM.

Appendix S3 Maps of predicted range modifications in the past for the three study species.

\section{DATA ACCESSIBILITY}

DNA sequences generated for this study were deposited in GenBank under accession numbers KM262595-KM262621. GenBank accession numbers of all other sequences used in this study are available in Appendix S1 in Supporting Information.

\section{BIOSKETCH}

Alice Latinne is interested in the evolution and diversity of murine rodents in Southeast Asia. She studies the evolutionary history of several murine species using phylogeographical and population genetic tools. She is currently working on the evolutionary dynamics of rodent-parasite interactions and uses parasites as markers of their host evolution.

Author contributions: A.L., C.N.M. and J.R.M. conceived the study; A.L., V.H., S.W. and S.M. collected data in the field; A.L. gathered the data and carried out the phylogenetic analyses; C.N.M. carried out the modelling; A.L. and C.N.M. wrote the paper.

Editor: John Stewart 